\title{
The effect of whole body vibration training on postural sway in patients with spinal cord injury: a pilot study
}

\author{
Yasuyoshi Asakawaa ${ }^{a}$ Myung-Mo Lee ${ }^{b}$, Chang-Ho Song ${ }^{c}$ \\ ${ }^{a}$ The Graduate School of Health Sciences, Gunma University, Gunma, Japan \\ ${ }^{b}$ Department of Physical Therapy, The Graduate School, Sahmyook University, Seoul, Republic of Korea \\ 'Department of Physical Therapy, College of Health and Welfare, Sahmyook University, Seoul, Republic of Korea
}

Objective: The aim of this study was to determine the impact of the application of whole body vibration training (WBV) on the balance ability of patients with an American Spinal Injury Association (ASIA) type C or D spinal cord injury.

Design: Randomized controlled trial.

Methods: Twelve patients with spinal cord injury were enrolled in this study. The participants were randomized to an experimental group $(n=6)$ or control group $(n=6)$. The subjects in the experimental group received WBV exercise and the control group received the sham exercise without vibration. The vibrations were adjusted vertically to the patient at a $30 \mathrm{~Hz}$ frequency and $3 \mathrm{~mm}$ amplitude. The whole body vibration lasted for 16 minutes in total including 5-minutes warm-up and cool-down at the beginning and end of the program, respectively. The static sitting balance ability was assessed by measuring the postural sway while sitting on the force plate with the eyes opened or closed. Postural sway length was measured for 30 seconds with a self-selected comfortable position.

Results: In the static balance test, the anterio-posterior, medio-lateral, and total postural sway length with the eyes open and closed was improved significantly before and after the intervention in the experimental group $(p<0.05)$. The experimental group showed significantly more improvement than the control group $(p<0.05)$.

Conclusions: Our results demonstrated that WBV training has a positive effect on improving static sitting balance and enhanced control of postural sway in patients with an ASIA-C or D type spinal cord injury.

Key Words: Postural balance, Spinal cord injury, Vibration

\section{Introduction}

Patients with a spinal cord injury tend to depend on wheelchairs for their daily routines. To restore everyday activities, they first need to recover balance in the seated position. On the other hand, spinal cord injury patients suffer from damage to the spinal motor nerves and sensory nerves, resulting in the loss of trunk, upper and lower limb strength as well as incomplete or complete sensory loss. In addition, they also have difficulties in maintaining or controlling a seated position [1]. To sustain the seated position without support, they require somatosensory coordination from the trunk and upper/lower limbs combined with visual information and vestibular senses, as well as an ability to use reflective adjustments [2,3].

Several studies have been conducted to improve the balance ability of spinal cord-injured patients. For them, the frequently-used interventions include game-based task-oriented balance training [4], balance training in a unsupported seated position [5], and laterally-moving kayak ergometer-based training [6,7]. On the other hand, most of the balance training interventions are limited only to a seated

Received: 12 October, 2013 Revised: 30 November, 2013 Accepted: 18 December, 2013

\section{Corresponding author: Chang-Ho Song}

Department of Physical Therapy, College of Health and Welfare, Sahmyook University, 815 Hwarang-ro, Nowon-gu, Seoul 139-742, Republic of Korea Tel: 82-2-3399-1637 Fax: 82-2-3399-1639 E-mail: Chsong@syu.ac.kr

(c) This is an Open-Access article distributed under the terms of the Creative Commons Attribution Non-Commercial License (http://creativecommons.org/licens es/by-nc/3.0) which permits unrestricted non-commercial use, distribution, and reproduction in any medium, provided the original work is properly cited.

Copyright $@ 2013$ Korean Academy of Physical Therapy Rehabilitation Science 
position or upper limb movement in a seated position, realizing only insignificant effectiveness to the lower limbs despite their importance in trunk balancing.

In recent decades, people have been increasingly interested in mechanical vibrations and many studies have examined the effects of mechanical vibrations on the human full body [8]. Whole body vibration is a dynamic stimulation delivering the shaking of vertical vibrating plates to the human body in an indirect manner [9]. A subject receiving this treatment steps on the vertical vibrating plates and experiences vibration through body segmentation to feel motor cortex activation adjustment, spinal motor nerve activation and muscular activation $[10,11]$. This vibration intervention has been found to improve not only the muscular strength and nerve roots that reduce muscular spasticity [12] but also the balancing ability of brain disease patients $[13,14]$ while preventing elderly collapse [15] and enhancing their ambulation $[16,17]$. Studies applying whole body vibration training (WBV) to the lower limbs of spinal cord injury patients include examinations of the bone density [18], muscular activation and blood flow rate [19], and spasticity of the quadriceps muscle of the thigh [11]. These studies, however, were mostly limited to the nerve roots and physiological changes, requiring more studies on how such physiological changes affect the functional movement of the spinal cord injury patients.

This study evaluated the impact of the application of whole body vibration training on the balance ability of patients with an American Spinal Injury Association (ASIA) type C, D spinal cord injury.

\section{Methods}

\section{Subjects}

This study surveyed 12 patients aged 20 to 50 , who were diagnosed with ASIA-C, D at D Rehabilitation Center in Uijeongbu province, South Korea. The subjects were selected based on the following inclusion criteria: (1) those who had passed at least 6 months from the spinal damage; (2) those who were regarded as ASIA-C by an ASIA evaluation; (3) those whose post-nerve damage muscular strength could resist at least $50 \%$ gravity; (4) those who could maintain a seated position independently for at least 30 seconds; (5) those who could change positions from seated to standing with no more than mid-level help from one assistant; (6) and those who could understand and follow a therapist's verbal command. The patients were excluded for the following reasons: (1) sustained sensory and motor damages due to a disease other than the spinal injury; (2) taking drugs that could affect the postural adjustment; (3) used an ancillary device for postural adjustment and could not receive whole body vibration exercise because of pregnancy, fracture, kidney stone, mechanical heart, blood clot, infectious disease, etc.; and (4) could not sit on a table independently by bending the hip joint at $65^{\circ}$ while standing on the floor. All experimental protocols and procedures were explained to each subject and were approved by the institutional review board of Sahmyook University. All subjects signed a consent form.

\section{Procedures}

This study was a randomized single trial design. The participants were randomized into the experimental group $(\mathrm{n}=6)$ and control group $(\mathrm{n}=6)$. Randomization was computer generated using a basic random number generator. The subjects in the experimental group practiced the WBV exercise and the control group practiced the sham exercise without vibration. WBV exercise was performed using a whole body vibrator (Turbosonic TT2590X7; TS-Korea Inc., Seoul, Korea). The vibrator creates precise vertical vibrations using sound waves with the application of a turbo sonic generator. This can be driven from low frequency, and the precise power can be controlled. In addition, the intensity (power) of the control, regardless of the frequency can be controlled separately, so the product is available from

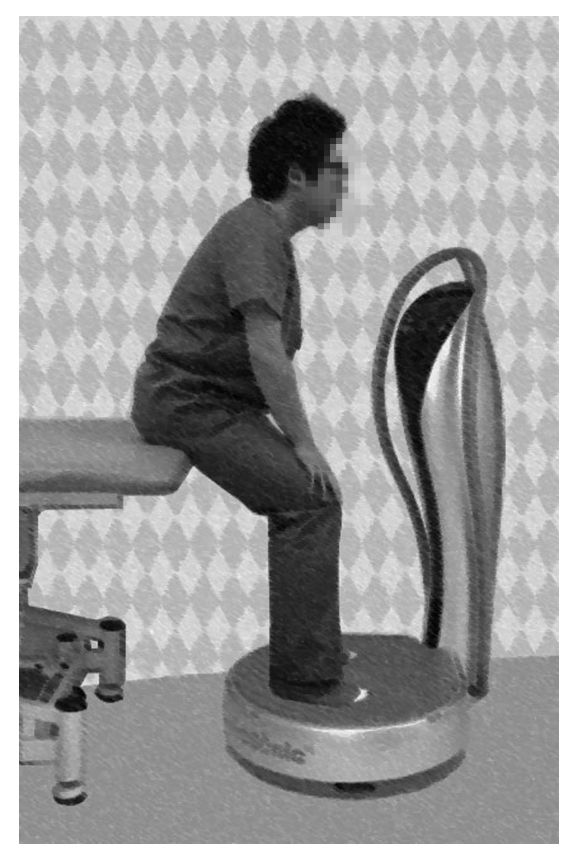

Figure 1. The application of whole body vibration training. 
the effective frequency of $1 \mathrm{~Hz}$. The working frequency was $3-25 \mathrm{~Hz} / 26-50 \mathrm{~Hz}$, and the operating frequency was $0.1 \mathrm{~Hz}-$ 100.000 Hz. The intensity could be controlled from 0 and 99 and the maximum permissible load was $230 \mathrm{~kg}$.

The subjects step on the machine by keeping their heels 8.4 inches away from each other and the valgus of both big toes at $9^{\circ}$ each. The vibrations were adjusted vertically to the patient at a $30 \mathrm{~Hz}$ frequency and $3 \mathrm{~mm}$ amplitude. To concentrate the vibrations on the pelvis, patients were instructed to bend their hips, knees and ankle joints at $65^{\circ}$, and sit lightly on a height-adjustable table. Their upper limbs were lowered to place their hands near the femur head so they would not influence the torso curve and pre-renal part (Figure 1). The whole body vibration lasted for 16 minutes in total including 5-minutes warm-up and cool-down at the beginning and end of the program, respectively. Four 45-seconds sets comprised one round [20].

\section{Outcome measures}

The balance ability was assessed by measuring the postural sway while sitting on the force plate with their eyes opened or closed. A force plate (PDM Multifunction Force Measuring Plate; Zebris, Baden-Wurttemberg, Germany, 2000) was used to measure the postural sway length for analyzing the balance ability. A total of 1504 force sensors embedded in every $1 \mathrm{~cm}^{2}$ on a plate $(32 \times 47 \mathrm{~cm})$ measured the static pressure of the buttocks when sitting $\left(1-120 \mathrm{~N} / \mathrm{cm}^{2}\right.$, 2-5 Hz). When measuring with their eyes open or closed, an assistant stood alongside for safety. The postural sway length was measured for 30 seconds with a self-selected comfortable position.

\section{Data analysis}

Statistical analysis was performed using SPSS ver. 17.0 (SPSS Inc., Chicago, IL, USA). The Shapiro-Wilk test was used to confirm that all outcome variables were normally distributed. A paired t-test was used to compare the depend-

Table 1. General characteristics of subjects

$(\mathrm{N}=12)$

\begin{tabular}{lcc}
\hline & Experimental group & Control group \\
\hline Gender (male/female) & $6(5 / 1)$ & $6(4 / 2)$ \\
Age $(\mathrm{yr})$ & $35.45(6.78)$ & $34.50(5.69)$ \\
Height $(\mathrm{cm})$ & $162.64(10.35)$ & $164.38(9.36)$ \\
Weight $(\mathrm{kg})$ & $59.41(12.14)$ & $60.81(11.86)$ \\
ASIA type $(\mathrm{C} / \mathrm{D})$ & $6(4 / 2)$ & $6(4 / 2)$ \\
\hline
\end{tabular}

Values are expressed as mean (SD).

ASIA: American Spinal Injury Association. ent variables within groups, whereas an independent t-test and $x^{2}$-test were used to compare the dependent variables of the between groups. $p$-values $<0.05$ were considered significant.

\section{Results}

Table 1 lists the general characteristics of the 12 subjects with a spinal cord injury who fulfilled the study inclusion criteria. No significant differences between the general characteristics or dependent variables of the two groups were detected at recruitment (Tables 1 and 2). In the static

Table 2. Comparison of postural sway within groups and between groups

\begin{tabular}{|c|c|c|c|}
\hline & $\begin{array}{l}\text { Experimental } \\
\text { group }(\mathrm{n}=6)\end{array}$ & $\begin{array}{c}\text { Control } \\
\text { group }(n=6)\end{array}$ & $\mathrm{t}^{\mathrm{b}}$ \\
\hline \multicolumn{4}{|l|}{ EO } \\
\hline \multicolumn{4}{|l|}{$\mathrm{AP}(\mathrm{cm})$} \\
\hline Pre & $59.84(11.31)$ & $58.27(10.62)$ & \multirow[t]{2}{*}{0.351} \\
\hline Post & $55.63(12.79)$ & $58.33(11.54)$ & \\
\hline Pre-Post & $-4.20(1.96)$ & $0.07(6.01)$ & \multirow[t]{2}{*}{$2.340^{*}$} \\
\hline $\mathrm{t}^{\mathrm{a}}$ & $7.441^{*}$ & 0.039 & \\
\hline \multicolumn{4}{|l|}{$\operatorname{ML}(\mathrm{cm})$} \\
\hline Pre & $53.84(10.24)$ & $50.77(10.41)$ & \multirow[t]{2}{*}{0.474} \\
\hline Post & $49.16(11.26)$ & $51.23(11.96)$ & \\
\hline Pre-Post & $-4.68(3.00)$ & $0.46(7.57)$ & \multirow[t]{2}{*}{$2.185^{*}$} \\
\hline $\mathrm{t}^{\mathrm{a}}$ & $5.430^{*}$ & 0.838 & \\
\hline \multicolumn{4}{|l|}{ Total $(\mathrm{cm})$} \\
\hline Pre & $98.70(13.30)$ & $96.39(14.03)$ & \multirow[t]{2}{*}{0.413} \\
\hline Post & $88.11(13.10)$ & $98.65(18.48)$ & \\
\hline Pre-Post & $-10.58(12.68)$ & $2.26(13.64)$ & \multirow[t]{2}{*}{$2.389^{*}$} \\
\hline $\mathrm{t}^{\mathrm{a}}$ & $2.891^{*}$ & 0.576 & \\
\hline \multicolumn{4}{|l|}{$\mathrm{EC}$} \\
\hline \multicolumn{4}{|l|}{$\mathrm{AP}(\mathrm{cm})$} \\
\hline Pre & $69.87(9.47)$ & $67.78(7.55)$ & \multirow[t]{2}{*}{0.597} \\
\hline Post & $62.15(4.70)$ & $68.06(8.40)$ & \\
\hline Pre-Post & $-7.72(10.61)$ & $0.28(5.55)$ & \multirow[t]{2}{*}{$2.316^{*}$} \\
\hline $\mathrm{t}^{\mathrm{a}}$ & $2.522^{*}$ & 0.176 & \\
\hline \multicolumn{4}{|l|}{$\mathrm{ML}(\mathrm{cm})$} \\
\hline Pre & $67.68(9.53)$ & $59.88(2.45)$ & \multirow[t]{2}{*}{1.243} \\
\hline Post & $59.88(12.45)$ & $62.00(8.31)$ & \\
\hline Pre-Post & $-7.80(6.42)$ & $-1.49(5.43)$ & \multirow[t]{2}{*}{$2.600^{*}$} \\
\hline $\mathrm{t}^{\mathrm{a}}$ & $4.207^{*}$ & 0.953 & \\
\hline \multicolumn{4}{|l|}{ Total $(\mathrm{cm})$} \\
\hline Pre & 105.23 (11.09) & $101.95(10.74)$ & \multirow[t]{2}{*}{0.735} \\
\hline Post & $95.98(8.01)$ & $102.81(8.16)$ & \\
\hline Pre-Post & $-9.25(12.52)$ & $0.85(6.21)$ & $2.505^{*}$ \\
\hline $\mathrm{t}^{\mathrm{a}}$ & $2.560^{*}$ & 0.478 & \\
\hline
\end{tabular}

Values are expressed as mean (SD).

EO: eyes opened, AP: anterio-posterior sway length, ML: mediolateral sway length, EC: eyes closed.

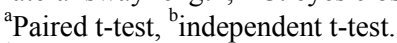
${ }^{*} p<0.05$. 
balance test, the anterio-posterior, medio-lateral, and total postural sway length with the eyes open and or closed was improved significantly before and after the intervention in the experimental group $(p<0.05)$, whereas the control group was not improved significantly. The experimental group showed significantly greater improvement than the control group $(p<0.05)$, suggesting that WBV exercise improves the static sitting balance ability in the experimental group (Table 2).

\section{Discussion}

This study revealed the positive effect of WBV training on improving the static sitting balance in patients with an ASIA-C type spinal cord injury affecting their lower limbs. WBV training reduced the anterio-posterior, medio-lateral, and total postural sway in the eye-open condition by $7.5 \%$ from $59.84 \mathrm{~cm}$ to $55.63 \mathrm{~cm}, 9.5 \%$ from $53.84 \mathrm{~cm}$ to 49.16 $\mathrm{cm}$, and $12 \%$ from $98.70 \mathrm{~cm}$ to $88.11 \mathrm{~cm}$, respectively, in the experimental group, whereas the values in the control group were increased by $0.1 \%$ from $58.27 \mathrm{~cm}$ to $58.33 \mathrm{~cm}, 0.9 \%$ from $50.74 \mathrm{~cm}$ to $51.23 \mathrm{~cm}$, and $2.3 \%$ from $96.39 \mathrm{~cm}$ to $98.65 \mathrm{~cm}$, respectively, after the intervention. Under the eye closed condition, the experimental group showed a significant decrease in the anterio-posterior, medio-lateral, and total postural sway of $11.0 \%$ from $69.87 \mathrm{~cm}$ to $62.15 \mathrm{~cm}$, $13.0 \%$ from $67.68 \mathrm{~cm}$ to $58.88 \mathrm{~cm}$, and $8.8 \%$ from 105.23 $\mathrm{cm}$ to $95.98 \mathrm{~cm}$, respectively, after WBV training, whereas in the control group these values increased by $0.4 \%$ from $67.78 \mathrm{~cm}$ to $68.06 \mathrm{~cm}, 3.5 \%$ from $59.88 \mathrm{~cm}$ to $62.00 \mathrm{~cm}$, and $0.8 \%$ from $101.95 \mathrm{~cm}$ to $102.81 \mathrm{~cm}$, respectively.

Although it is difficult to compare the results directly because there has not been any research using WBV to improve the balancing ability of spinal cord injury patients, the present research suggests that mechanical stimuli activates the muscle spindle to induce the activity of $\alpha$-motor neurons [21]. A similar effect of whole body vibration exercise has also been observed in spinal cord injury patients. Herrero et al. [19] reported that WBV training for spinal cord injury patients increased the lower limb blood flow rate and speed, and activated vastas medialis and vastus lateralis muscles. They also reported that the main reason for the activated vastas medialis and vastus lateralis muscles was that WBV acted on the sensory receptors of the muscles and tendons to activate the $\alpha$-motor neurons and muscle spindle, thereby inducing atonic vibration reflex from the corresponding muscles [19]. Although this study did not measure lower limb muscular activation, the WBV is believed to have stimulated the muscle spindles of spinal cord injury patients, increased the proprioceptive sense inputs through the afferent nerves to stimulate the postural adjustment sensory organs [22,23], and enhanced their sitting balance.

The energy metabolism becomes more activated with increasing frequency of WBV, requiring more oxygen consumption [19]. Hence, the increased work out. In this study, WBV stimulation was adjusted to a $30 \mathrm{~Hz}$ frequency and a $3 \mathrm{~mm}$ amplitude to use on spinal cord injury patients while allowing them bend their knees by $65^{\circ}$ (full extension: 0 degree). Unlike previous studies taking a passive standing position that allowed the knee also absorb some of the vibrations, this study concentrated on stimulating the pelvis by making the subjects stand while leaning on the table.

Body balance is maintained by comprehensive motor adjustment ability supported by sight, vestibular sense and somatosensory system [24]. On the other hand, patients with a spinal cord injury suffer from muscle weakening and paralysis, as well as damaged somatosensory transmission [25]. To deal with this, whole body vibration exercise is a safe and effective way of exercising to activate the muscles of spinal cord injury patients. This study was limited by the absence of measuring the lower limb muscular strength, which might be a direct factor in improving the balancing ability, and the invariance of stimulation factors, such as vibration frequency, amplitude, and the degree of knee bending, which could be significant variables in its application.

WBV training applied to the lower limbs in patients with an ASIA C type spinal cord injury improved their static sitting balance. This data is expected provide physical therapists with the appropriate scientific evidence to justify the WBV treatment of patients with an ASIA-C or D type spinal cord injuries in clinical practice.

\section{References}

1. Jørgensen V, Elfving B, Opheim A. Assessment of unsupported sitting in patients with spinal cord injury. Spinal Cord 2011;49: 838-43.

2. Dean C, Shepherd R, Adams R. Sitting balance I: trunk-arm coordination and the contribution of the lower limbs during self-paced reaching in sitting. Gait Posture 1999;10:135-46.

3. Dean CM, Shepherd RB, Adams RD. Sitting balance II: reach direction and thigh support affect the contribution of the lower limbs when reaching beyond arm's length in sitting. Gait Posture 1999;10:147-53.

4. Betker AL, Desai A, Nett C, Kapadia N, Szturm T. Game-based exercises for dynamic short-sitting balance rehabilitation of peo- 
ple with chronic spinal cord and traumatic brain injuries. Phys Ther 2007;87:1389-98.

5. Boswell-Ruys CL, Harvey LA, Barker JJ, Ben M, Middleton JW, Lord SR. Training unsupported sitting in people with chronic spinal cord injuries: a randomized controlled trial. Spinal Cord 2010;48:138-43.

6. Bjerkefors A, Carpenter MG, Thorstensson A. Dynamic trunk stability is improved in paraplegics following kayak ergometer training. Scand J Med Sci Sports 2007;17:672-9.

7. Grigorenko A, Bjerkefors A, Rosdahl H, Hultling C, Alm M, Thorstensson A. Sitting balance and effects of kayak training in paraplegics. J Rehabil Med 2004;36:110-6.

8. Slatkovska L, Alibhai SM, Beyene J, Cheung AM. Effect of whole-body vibration on BMD: a systematic review and meta-analysis. Osteoporos Int 2010;21:1969-80.

9. Sayenko DG, Masani K, Alizadeh-Meghrazi M, Popovic MR, Craven BC. Acute effects of whole body vibration during passive standing on soleus H-reflex in subjects with and without spinal cord injury. Neurosci Lett 2010;482:66-70.

10. Mileva KN, Bowtell JL, Kossev AR. Effects of low-frequency whole-body vibration on motor-evoked potentials in healthy men. Exp Physiol 2009;94:103-16.

11. Ness LL, Field-Fote EC. Effect of whole-body vibration on quadriceps spasticity in individuals with spastic hypertonia due to spinal cord injury. Restor Neurol Neurosci 2009;27:621-31.

12. Musumeci G, Loreto C, Leonardi R, Castorina S, Giunta S, Carnazza ML, et al. The effects of physical activity on apoptosis and lubricin expression in articular cartilage in rats with glucocorticoid-induced osteoporosis. J Bone Miner Metab 2013;31: 274-84.

13. van Nes IJ, Geurts AC, Hendricks HT, Duysens J. Short-term effects of whole-body vibration on postural control in unilateral chronic stroke patients: preliminary evidence. Am J Phys Med Rehabil 2004;83:867-73.

14. Turbanski S, Haas CT, Schmidtbleicher D, Friedrich A, Duisberg P. Effects of random whole-body vibration on postural control in Parkinson's disease. Res Sports Med 2005;13:243-56.

15. Bruyere O, Wuidart MA, Di Palma E, Gourlay M, Ethgen O, Richy F, et al. Controlled whole body vibration to decrease fall risk and improve health-related quality of life of nursing home residents. Arch Phys Med Rehabil 2005;86:303-7.

16. Kawanabe K, Kawashima A, Sashimoto I, Takeda T, Sato Y, Iwamoto J. Effect of whole-body vibration exercise and muscle strengthening, balance, and walking exercises on walking ability in the elderly. Keio J Med 2007;56:28-33.

17. Iwamoto J, Sato Y, Takeda T, Matsumoto H. Whole body vibration exercise improves body balance and walking velocity in postmenopausal osteoporotic women treated with alendronate: Galileo and Alendronate Intervention Trail (GAIT). J Musculoskelet Neuronal Interact 2012;12:136-43.

18. Davis R, Sanborn C, Nichols D, Bazett-Jones DM, Dugan EL. The effects of whole body vibration on bone mineral density for a person with a spinal cord injury: a case study. Adapt Phys Activ Q 2010;27:60-72.

19. Herrero AJ, Menéndez H, Gil L, Martín J, Martín T, GarcíaLópez D, et al. Effects of whole-body vibration on blood flow and neuromuscular activity in spinal cord injury. Spinal Cord 2011;49:554-9.

20. van Nes IJ, Latour H, Schils F, Meijer R, van Kuijk A, Geurts AC. Long-term effects of 6-week whole-body vibration on balance recovery and activities of daily living in the postacute phase of stroke: a randomized, controlled trial. Stroke 2006;37:2331-5.

21. De Gail P, Lance JW, Neilson PD. Differential effects on tonic and phasic reflex mechanisms produced by vibration of muscles in man. J Neurol Neurosurg Psychiatry 1966;29:1-11.

22. Roll JP, Vedel JP, Ribot E. Alteration of proprioceptive messages induced by tendon vibration in man: a microneurographic study. Exp Brain Res 1989;76:213-22.

23. Verschueren SM, Swinnen SP, Desloovere K, Duysens J. Vibration-induced changes in EMG during human locomotion. J Neurophysiol 2003;89:1299-307.

24. Priplata AA, Patritti BL, Niemi JB, Hughes R, Gravelle DC, Lipsitz LA, et al. Noise-enhanced balance control in patients with diabetes and patients with stroke. Ann Neurol 2006;59: 4-12.

25. Coleman WP, Geisler FH. Injury severity as primary predictor of outcome in acute spinal cord injury: retrospective results from a large multicenter clinical trial. Spine J 2004;4:373-8. 